\title{
Preferensi kepustakaan penelitian di bidang ilmu Pendidikan Pancasila dan Kewarganegaraan (PPKn)
}

\author{
Fauzi Abdillah ${ }^{\mathrm{a}, 1^{*}}$ \\ a Pendidikan Pancasila dan Kewarganegaraan, Universitas Negeri Jakarta, Indonesia \\ 1 abdillah@unj.ac.id \\ *korespondensi penulis
}

\section{ABSTRAK}

Secara keilmuan Pendidikan Pancasila dan Kewarganegaraan (PPKn) tergolong sebagai kajian baru daripada ilmu lainnya. Idealnya, PPKn dieksplorasi dan dikembangkan berdasar pada kajian penelitian terdahulu, namun kemunculan PPKn di Indonesia yang lebih bernuansa imperatif daripada santifik, membuatnya memiliki jalur dan bentuk yang unik. Penelitian ini bertujuan untuk memetakan di mana posisi para sarjana dan sumber apa yang lebih banyak digunakan oleh mereka untuk mengkaji PPKn di Indonesia. Metode penelitian e-research dengan mengumpulkan database Google Scholar digunakan dalam penelitian ini. Pengumpulan data tersebut menggunakan Harzing dengan kata kunci yang dimaksud. Data yang terkumpul kemudian direduksi, diorganisasi, dan ditabulasi untuk mendapatkan gambaran yang dimaksud. Temuan dari penelitian ini mengungkapkan bahwa jumlah sitasi pada buku lebih banyak daripada artikel penelitian. Hal tersebut bisa dimaknai bahwa sumber buku yang dijadikan pustaka cenderung membuat laju keilmuan dan keluasan PPKn sebagai ilmu berada pada jalur lambat. Rekomendasi yang muncul dari penelitian ini tentu sarjana PPKn perlu memprioritaskan artikel penelitian terkini sebagai sumber primer. Hal ini dapat dimulai dari tingkat pendidikan sarjana, karena hasil skripsi terdeteksi banyak mewarnai indeksasi tersebut

\section{ABSTRACT}

Indonesian Civic and Citizenship Literature Preference. Indonesian Civic Education, known as Pancasila dan Pendidikan Kewarganegaraan (PPKn), is classified as a new study than other sciences. Ideally, PPKn is explored and developed based on previous research studies. However, the emergence of PPKn in Indonesia, which is more imperative than scientific, makes it have a unique path and form. This study aims to map the scholars' positions and what sources are mostly used by them to study PPKn in Indonesia. The e-research research method by collecting the Google Scholar database was used in this study. The data collection uses Harzing with the keywords in question. The collected data is then reduced, organized, and tabulated to obtain the intended picture. This study's findings that the number of citations in books is greater than that of research articles. This finding can be interpreted that the source of books used as literature tends to make the science and breadth of PPKn a science on a slow path. The recommendations that emerge from this research are that PPKn scholars need to prioritize current research articles as primary sources. The recommendations can be started from the undergraduate education level because the thesis results were detected dominating the indexation.

\author{
Informasi Artikel \\ Diterima : 10 Juli 2020 \\ Kata kunci: \\ PPKn \\ Kajian Pustaka PPKn \\ Buku PPKn \\ Penelitian PPKn \\ Literatur PPKn
}

Disetujui: 22 Agustus 2020

\section{Pendahuluan}

Adagium "penelitian yang baik ditunjang pula oleh hasil penelitian terdahulu yang baik juga" berlaku untuk semua bidang ilmu. Perkembangan praktik dan kebijakan pendidikan selaras dengan pengembangan ilmu pengetahuan. Namun, kebijakan berbasis penelitian belum menjadi mainstream bagi pemangku kebijakan pendidikan. Perspektif kebijakan berbasis penelitian tidak banyak dilirik karena penelitian pendidikan belum banyak dilaksanakan secara mencukupi. Penelitian dasar yang 
berkualitas dan mutakhir, merupakan salah satu pijakan yang prospektif untuk meningkatkan kualitas penelitian. Sehingga, terjadi keberlanjutan, inovasi dan temuan baru dalam bidang yang diteliti.

Disiplin Pendidikan Kewarganegaraan yang secara keilmuan terus berkembang, tentu perlu juga pasokan riset dasar yang bermutu dan komprehensif. Namun, dari pengamatan yang telah dilakukan, sejauh ini menganggap bahwa penelitian bidang ini di Indonesia masih dalam kondisi yang sporadis, tumpang tindih, dan duplikasi. Hal ini ditengarai karena para peneliti, belum mendapatkan wawasan dasar dalam pengembangan tema dan topik penelitian. Tema dan topik penelitian bisa berangkat dari permasalahan nyata di lapangan dan gap teoretis dalam disiplin keilmuan.

Dalam rangka mengisi kekosongan tersebut, artikel ini memaparkan temuan penelitian yang dilaksanakan untuk mengetahui sejauh mana publikasi karya ilmiah di bidang PKn membentangkan garapannya, dan sampai mana kita selaku peneliti berhenti agar tidak tumpang tindih dengan keilmuan lainnya. Belum lagi, sebagai bagian dari ilmu sosial, di berbagai pemeringkatan sitasi, tingkat sitasi pada bidang sosial humaniora lebih rendah daripada bidang sains, teknonologi, teknik dan matematika. (Harzing A. W., 2020) Maka, tentu perlu ada spesifikasi dalam penentuan peta jalan penelitian.

Di era digital, pemetaan bisa dilaksanakan secara strategis melalui mesin pencari. Penggunaan Google Scholar sebagai analisis sitasi, disebut sebagai demokratisasi karena memberikan akses untuk mengakses sumber yang komprehensif (Harzing \& Ron van der Wal, 2008). Studi yang membahas Google Scholar dengan metode perbandingan, pemanfaatan, dan lain sebagainya telah banyak dilakukan. (Callicott \& Vaughn, 2005; Gardner \& Eng, 2005; Giustini, 2005; Levine-Clark \& Kraus, 2007; Meier \& Conkling, 2008; Bramer, Giustini, Kramer, \& Anderson, 2013; Gehanno, Rollin, \& Darmoni, 2013; Știrbu, Thirion, Schmitz, Haesbroeck, \& Greco, 2015; Breeding, 2015; Martin-Martin, Orduna-Malea, Harzing, \& López-Cózar, 2016)

Penelitian dasar yang memetakan, mengkategorikan, dan menganalisis karya terbitan sarjana PPKn di Indonesia secara digital belum pernah dilakukan. Padahal, studi tersebut bermanfaat untuk melihat prospek area riset (Abreu \& Almeida, 2018) dan pemetaan area riset seperti studi landscape bidang disain dalam 12 tahun terakhir di Inggris. (Rodgers, Mazzarella, \& Conerney, 2019). Adapun, studi penelusuran research landscape yang telah dilakukan meliputi studi mengenai solusi berbasis Internet of Things (IOT) untuk permasalahan negara Vietnam (T. Cao et al., 2016), pencarian core disipline untuk Bussines Intelligence dan Big Data (Liang \& Liu, 2018), dan sintesis bagaimana konsep smart city (Ojo, Dzhusupova, \& Curry, 2015).

Disiplin Pendidikan Kewarganegaraan sebagai salah satu area ilmu pendidikan membutuhkan studi yang serupa. Diskursus yang kolaboratif, beragam, dan aplikasi menjadi ladang penyelidikan filsafat pendidikan kontemporer untuk pendidikan. (Watson, 2016) Demi berkontribusi dalam diskursus tersebut, maka artikel memberikan data mutakhir mengenai research landscape Disiplin Pendidikan Kewarganegaraan. Penelitian ini dibatasi pada karya ilmiah yang terlacak oleh Google Scholar, diterbitkan periode 2010-2020, ditulis oleh warga negara Indonesia, dan terbatas pada kajian PPKn.

\section{Metode}

Penelitian ini menggunakan pendekatan berbasis internet atau e-research. Melalui pendekatan ini peneliti melakukan eksplorasi secara mendalam terhadap program, kejadian, proses, aktivitas, 
terhadap satu atau lebih orang secara elektronik. Pendekatan ini berangkat dari dua asumsi, yakni situs dan halaman di World Wide Web (WWW) adalah objek analisis; dan Online Communication berarti mengumpulkan data dari individu atau organisasi. (Bryman, 2012) Desain yang digunakan adalah Online Social Web Surveys. Obyek analisis dalam penelitian ini adalah dokumen ilmiah yang terlacak oleh Google Scholar pada periode 2010-2020 dengan kata kunci tertentu. Mengacu pada Gambar 2, pengumpulan data dilaksanakan dengan menggunakan perangkat lunak Harzing's Publish or Perish (macOS GUI edition) karya Anne-Wil Harzing (Harzing A. W., 2010), adapun kata kunci yang digunakan meliputi:

\begin{tabular}{llll}
\hline NO & KATA KUNCI & PERIODE & $\begin{array}{l}\text { ASAL } \\
\text { PENULIS }\end{array}$ \\
\hline 1 & Pendidikan Kewarganegaraan & 2010-2020 & Indonesia \\
2 & Pendidikan Pancasila dan Kewarganegaraan & \\
3 & PPKn & \\
4 & PKn & \\
5 & Civic Education & \\
6 & Citizenship Education & \\
\hline
\end{tabular}

Data yang terkumpul kemudian akan disaring beberapa kriteria: (1) Dokumen merupakan terbitan ilmiah berupa artikel jurnal, artikel prosiding, buku ISBN; (2) Dokumen diterbitkan oleh lembaga bereputasi; (3) Dokumen ditulis oleh warga negara Indonesia; (4) Konten kajian dalam dokumen relevan dengan konteks Pendidikan Pancasila dan Kewarganegaraan. Analisis data dibantu oleh software NVivo 11 for Mac dengan melaksanakan coding pada tiap tahapannya.

\section{Hasil dan Pembahasan}

Penelusuran dokumen pada pertengahan Agustus 2020 dengan menggunakan perangkat lunak Harzing's Publish or Perish berdasarkan kata kunci setelah melalui proses pengumpulan dan penghapusan data yang ganda, adalah sebagai berikut:

Kata kunci yang digunakan tentu akan membantu kami menyaring dahulu 1000 dokumen teratas pada 10 tahun terakhir. Setelah dikumpulkan, kemudian pemeriksaan kedua adalah penghapusan yang tidak sesuai bidang ilmu Pendidikan Kewarganegaraan.

Tabel 1 Kata kunci yang digunakan untuk menjaring karya publikasi

\begin{tabular}{lll}
\hline NO & KATA KUNCl & TERKUMPUL \\
\hline 1 & Pendidikan Kewarganegaraan & 1000 \\
2 & Pendidikan Pancasila dan Kewarganegaraan & 680 \\
3 & PPKn & 810 \\
4 & PKn & 999 \\
5 & Civic Education & 987 \\
6 & Citizenship Education & 1000 \\
\hline Jumlah & 5476 \\
\hline
\end{tabular}

Setelah itu, data sejumlah 5476 itu diperiksa kembali untuk menemukan data duplikasi atau ganda, lalu menghapus penulis yang berasal dari luar negeri, dan tulisan yang di luar bidang keilmuan Pendidikan kewarganegaraan. Dari hasil pemilahan tersebut maka tersisa 3492 judul artikel yang dipublikasikan sepuluh tahun terakhir, visualisasi data tersebut bisa lihat di bawah ini. 


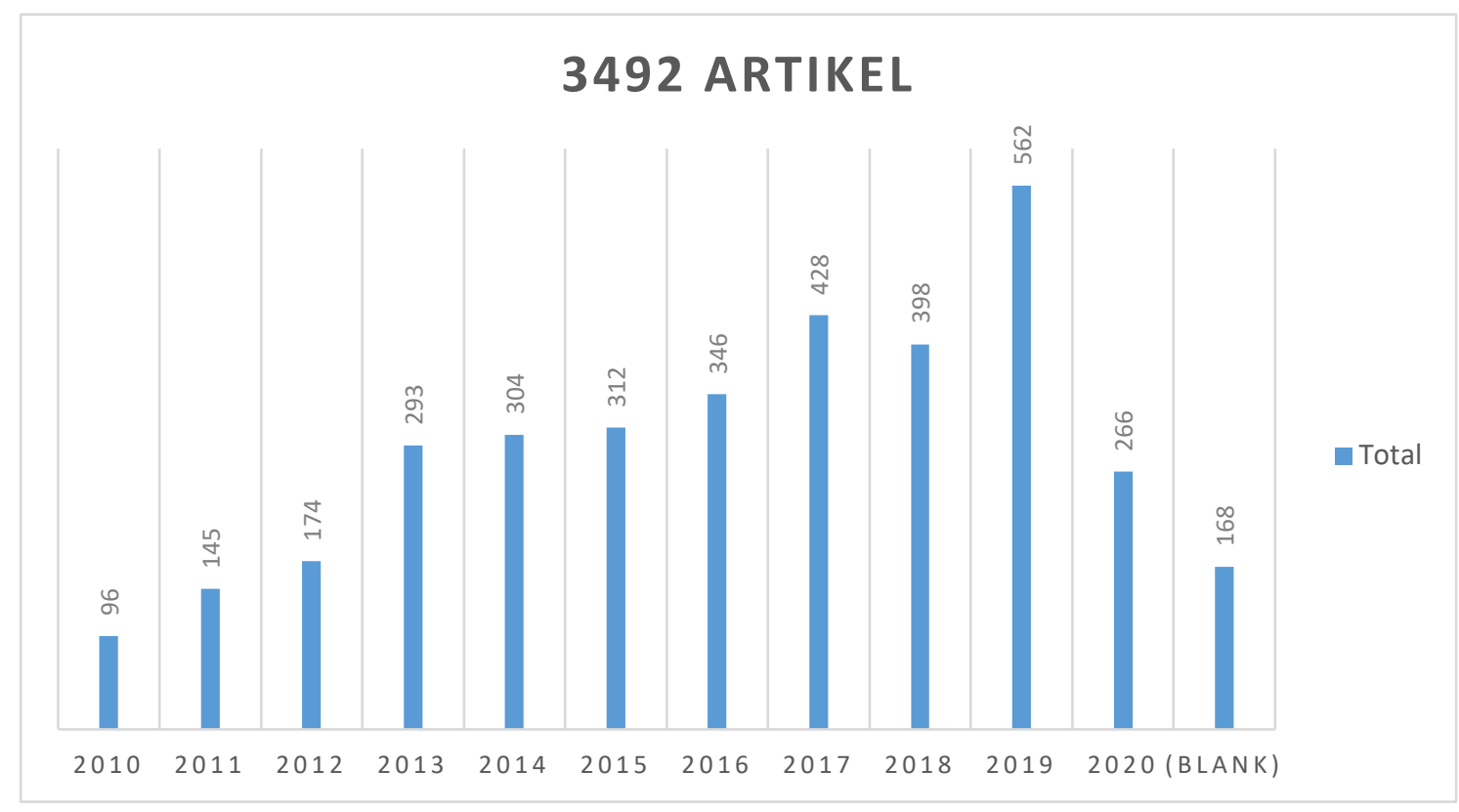

Grafik 1 Hasil Pemilahan Data

Terdapat dokumen yang mengalami galat, sehingga tidak teridentifikasi tahun publikasinya, yang berjumlah 174 .

Secara internasional, penulis dari Indonesia ditemukan sebanyak 143 karya pakai term civic education, lima karya memakai istilah citizenship education. Komunitas internasional lebih banyak menggunakan istilah citizenship education, terlebih pembahasannya memang bukan di kurikuler, tetapi lebih ke sosiokultural.

Tabel 2 Pemeringkatan Jumlah Sitasi pada Bidang PKn tingkat internasional

\begin{tabular}{llllll}
\hline No & Karya & & Penulis & Tahun $\begin{array}{l}\text { Jumlah } \\
\text { Sitasi }\end{array}$ \\
\hline 1. & Diversity, group identity, and citizenship JA Banks & 2014 & 1421
\end{tabular}
education in a global age

2. Soft versus critical global citizenship education VO de Andreotti $2014 \quad 835$

3. Citizenship for the 21st century: An international J Cogan, R 2014676 perspective on education

Derricott

4. Towards a framework for critical citizenship L Johnson, P 2010334 education Morris

5. The handbook of practice and research in study R Lewin $\quad 2010 \quad 310$ abroad: Higher education and the quest for global citizenship

6. Non-production benefits of education: Crime, LLochner 2011289 health, and good citizenship

7. Strategi pembelajaran PPKN $\quad$ E Solihatin $2012 \quad 284$

8. Initial Findings from the IEA International Civic W Schulz, J 2010238 and Citizenship Education Study. Ainley, J Fraillon,

D Kerr, B Losito

9. Penguatan pendidikan kewarganegaraan untuk D Budimansyah $2010 \quad 203$ membangun karakter bangsa 
10. Citizenship and citizenship education in a Olchilov

2013194 changing world

11. Teacher interpretations of citizenship education: A Osler

2011194

National identity, cosmopolitan ideals, and political realities

12. Rethinking citizenship education: A curriculum for participatory democracy

13. Digital media literacy education and online civic and political participation

T McCowan $2011 \quad 194$

J Kahne, NJ Lee, 2012188 JT Feezell

14. Nonproduction benefits of education: Crime, L Lance health, and good citizenship

15. Review of the effects of citizenship education

E Geboers, F $2013 \quad 168$
Geijsel, W W
Admiraal, G ten
Dam

16. We cannot teach what we don't know: Indiana A Rapoport 2010 teachers talk about global citizenship education

17. The longings and limits of global citizenship education: The moral pedagogy of schooling in a cosmopolitan age

18. The global dimension in education and education for global citizenship: Genealogy and critique

G Mannion, G
Biesta, $M$
Priestley, et.al/

19. Citizenship education in England 2001-2010: young people's practices and prospects for the future: the eighth and final report from the A Keating, D Citizenship Education ...

20. Global citizenship education: Everyday Mundy, J Lopes

2011 transcendence

Dalam pentas internasional, pada peringkat 20 sitasi terbanyak kita bisa melihat ada dua karya ilmuwan PKn asal Indonesia yang banyak dikutip, dan bentuknya sebuah buku bukan artikel penelitian. Sedangkan, peneliti juga mengkategorisasikan 20 karya terbanyak disitasi dalam sepuluh tahun terakhir di bawah.

Tabel 3 Dua puluh karya sarjana Indonesia di bidang PPKn terbanyak disitasi dalam sepuluh tahun terakhir

\begin{tabular}{|c|c|c|c|c|}
\hline No & Karya & Penulis & Tahun & $\begin{array}{l}\text { Jumlah } \\
\text { Sitasi }\end{array}$ \\
\hline 1. & Strategi pembelajaran PPKN & E Solihatin & 2012 & 284 \\
\hline 2. & $\begin{array}{l}\text { Penguatan pendidikan kewarganegaraan untuk } \\
\text { membangun karakter bangsa }\end{array}$ & D Budimansyah & 2010 & 203 \\
\hline 3. & $\begin{array}{l}\text { Pendidikan Kewarganegaraan Republik } \\
\text { Indonesia }\end{array}$ & M Erwin & 2011 & 90 \\
\hline 4. & Pengantar pendidikan kewarganegaraan & H Darmadi & 2017 & 79 \\
\hline 5. & Pendidikan Kewarganegaraan & Zl Amin & 2014 & 76 \\
\hline 6. & Pendidikan kewarganegaraan & $\begin{array}{l}\text { MS Kaelan, A } \\
\text { Zubaidi }\end{array}$ & 2010 & 73 \\
\hline
\end{tabular}


7. Urgensi Pendidikan Pancasila dan H Darmadi $2013 \quad 70$ Kewarganegaraan di perguruan tinggi

8. Pendidikan Kewarganegaraan Berbasis Nilai IK Aryani, M $2010 \quad 68$ Susatim, A Jamaludin

9. Civic education: antara realitas politik dan J Hamidi, M Lutfi 201068 implementasi hukumnya

10. Pendidikan Kewarganegaraan dalam perspektif US Winataputra $2012 \quad 65$ pendidikan untuk mencerdaskan kehidupan bangsa (gagasan, instrumentasi, dan praksis)

11. Pendidikan Pancasila dan Kewarganegaraan AS Rahayu $2017 \quad 63$ (PPKn)

12. Penerapan lesson study berbasis musyawarah guru mata pelajaran (MGMP) terhadap peningkatan kompetensi profesional guru PKN SMP se-kabupaten Ogan Ilir

13. Peranan Pendidikan Kewarganegaraan Dalam Membina Sikap Toleransi Antar Siswa

14. Penerapan Model Pembelajaran Discovery WB Sulfemi 201952 Learning Meningkatkan Motivasi Dan Hasil Belajar Pendidikan Kewarganegaraan

15. Pengaruh lingkungan belajar terhadap prestasi belajar mahasiswa PPKn angkatan 2008/2009 R Anggara, U $2012 \quad 59$ Chotimah Universitas Ahmad Dahlan

16. The effect of contextual learning in civic K Komalasari $2012 \quad 42$ education on students' civic skills

17. Integrasi Pendidikan Karakter dalam P Dianti $2014 \quad 40$ pembelajaran Pendidikan Kewarganegaraan untuk mengembangkan karakter siswa

18. Pembelajaran PPKn (Teori Pengajaran Abad 21 di $\mathrm{SD} / \mathrm{MI})$

19. Pendidikan Kewarganegaraan (Civic Education); Demokrasi Hak Asasi Manusia dan Masyarakat Rozak Madani

20. The Policies on Civic Education in Developing ES Nurdin $2015 \quad 37$ National Character in Indonesia.

Di atas, kita bisa melihat, kembali jenis buku banyak mendominasi daripada karya ilmiah lainnya. Maka bisa kita ketahui, kecenderungan untuk meneliti yang seperti terbatas pada civic kurikuler menjadi lebih tinggi. Karya penelitian yang baik harusnya ditunjang oleh karya penelitian yang baik pula. Sehingga, kebaruan akan didapatkan oleh penelitian PKn di masa depan (Abreu \& Almeida, 2018; Rodgers, Mazzarella, \& Conerney, 2019)

Tentu generalisasi tidak dapat dilakukan pada studi ini, mengingat keterbatasan penelitian yang hanya memetakan data Google Scholar saja tidak bisa disebut mencukupi (Meier \& Conkling, 2008; Gehanno, Rollin, \& Darmoni, 2013). Ditemukannya pola atas jenis publikasi yang mendominasi, yaitu dari studi akhir mahasiswanya, memperlihatkan bahwa justru karya ilmiah yang belum dalam bentuk 
siap publikasi seperti itu menarik banyak peneliti selanjutnya untuk dipelajari dan dikutip. Padahal mulai dari skripsi, tesis, dan disertasi adalah tugas belajar meneliti, sehingga kemungkinan ketidaklengkapan sampai kekeliruan masih ada pada karya tersebut. Rekomendasi untuk para peneliti pada disiplin PPKn selanjutnya adalah untuk kutip karya ilmiah yang telah dipublikasikan pada jurnal yang ketat proses editorialnya sehingga termasuk pada karya yang layak untuk disitasi.

\section{Simpulan}

Dari data yang telah terkumpul bisa dilihat bahwa sumber buku teks masih mendominasi sitasi dalam penelitian dan karya ilmiah lainnya di Google Scholar dalam sepuluh tahun terakhir. Dalam studi ini teridentifikasi bahwa terminologi civic education lebih banyak digunakan di pentas internasional daripada Citizenship Education oleh para sarjana PKn di Indonesia. Hal tersebut memperlihatkan juga bahwa dalam sepuluh terakhir artikel yang dipublikasikan memang banyak berkutat pada strategi pembelajaran, media, dan bahan ajar. Namun, hal tersebut perlu diteliti kembali, karena identifikasi awal terlihat bahwa karya akhir pendidikan sarjana seperti skripsi, cukup mendominasi mesin pencarian karena diupload secara utuh melalui sistem repository dan lainnya.

\section{Ucapan Terimakasih}

Penelitian ini didanai oleh Fakultas IImu Sosial Universitas Negeri Jakarta pada tahun 2020 dengan nomor kontrak 685.A/UN39/KU.00.01/2020.

\section{Referensi}

Abreu, R., \& Almeida, F. (2018). E-learning in mixed reality landscape: emerging issues and key trends in scientific research. In L. G. Chova, A. L. Martínez, \& I. C. Torres (Ed.), 12th International Technology, Education and Development Conference (pp. 6181-6187). Valencia: IATED.

Bramer, W. M., Giustini, D., Kramer, B. M., \& Anderson, P. (2013). The comparative recall of Google Scholar versus PubMed in identical searches for biomedical systematic reviews: a review of searches used in systematic reviews. Systematic reviews, 2(1), 115.

Breeding, M. (2015). The future of library resource discovery. Baltimore: NISO Whitepapers.

Bryman, A. (2012). Social Research Methods (Fourth Edition ed.). Oxford: Oxford University Press.

Callicott, B., \& Vaughn, D. (2005). Google Scholar vs. Library Scholar: Testing the Performance of Schoogle. Internet Reference Services Quarterly, 10(3), 71-88.

Gardner, S., \& Eng, S. (2005). Gaga over Google? Scholar in the Social Sciences. Library Hi Tech News, 22(8), 42-45.

Gehanno, J. F., Rollin, L., \& Darmoni, S. (2013). Is the coverage of Google Scholar enough to be used alone for systematic reviews. BMC Medical Informatics and Decision Making, 13(7).

Giustini, D. (2005). How Google is changing medicine. BMJ, 331(7531), 1487-1488.

Harzing, A. W. (2010). The publish or perish book. Tarma Software Research Pty Limited.

Harzing, A. W. (2020). Everything you always wanted to know about research impact. In T. Clark, \& M. Wright, How to get published in the best management journals. Edward Elgar Publishing. 
Harzing, A. W., \& Ron van der Wal. (2008). Google Scholar as a new source for citation analysis? Ethics in Science and Environmental Politics, 8(1), 61-73.

Levine-Clark, M., \& Kraus, J. (2007). Finding Chemistry Information Using Google Scholar. Science \& Technology Libraries, 27(4), 3-17.

Liang, T.-P., \& Liu, Y.-H. (2018). Research Landscape of Business Intelligence and Big Data analytics: A bibliometrics study. Expert Systems With Applications, 111, 2-10. DOI: https://doi.org/10.1016/j.eswa.2018.05.018.

Martin-Martin, A., Orduna-Malea, E., Harzing, A. W., \& López-Cózar, E. D. (2016). Can we use Google Scholar to identify highly-cited documents? Journal of Informetrics, 11(1), 152-163.

Meier, J. J., \& Conkling, T. W. (2008). Google Scholar's Coverage of the Engineering Literature: An Empirical Study. Journal of Academic Librarianship, 34(3), 201.

Ojo, A., Dzhusupova, Z., \& Curry, E. (2015). Exploring the Nature of the Smart Cities Research Landscape. In T. A. R. Gil-Garcia, Smarter as the New Urban Agenda: A Comprehensive View of the 21st Century City. Springer.

Rodgers, P., Mazzarella, F., \& Conerney, L. (2019). The Evolving Landscape of Design Research in the UK. International Association of Societies of Design Research Conference 2019 (pp. 1-16). Manchester: Manchester Metropolitan University.

Știrbu, S., Thirion, P., Schmitz, S., Haesbroeck, G., \& Greco, N. (2015). The utility of Google Scholar when searching geographical literature: comparison with three commercial bibliographic databases. The Journal of Academic Librarianship, 41(3), 322-329.

T. Cao et al. (2016). IoT Services for Solving Critical Problems in Vietnam: A Research Landscape and Directions. IEEE Internet Computing, 20(5), 76-81. DOI: 10.1109/MIC.2016.97.

Watson, L. (2016). The Epistemology of Education. Philosophy Compass, 11(3), 146-159. DOI: https://doi.org/10.1111/phc3.12316. 